\title{
A CASE REPORT OF KRUKENBERG TUMOR'S SECONDARY TO ADENOCARCINOMA OF GALL BLADDER.
}

Seshu lakshmi' ${ }^{1}$ Venkata Umakant ${ }^{2}$, Rajeev Donepudi ${ }^{3}$, Pavani ${ }^{4}$, Bhuvan Krishna ${ }^{5}$.

\section{HOW TO CITE THIS ARTICLE:}

Seshu lakshmi, Venkata Umakant, Rajeev Donepudi, Pavani, Bhuvan Krishna. "A case report of krukenberg tumor's secondary to adenocarcinoma of gall bladder". Journal of Evolution of Medical and Dental Sciences 2013; Vol2, Issue 27, July 8; Page: 4997-5001.

ABSTRACT: Metastasis to the ovary is not rare and 5\% to $10 \%$ of all ovarian malignancies are metastasis. Ovarian secondary tumors arise most commonly from primary tumors of stomach. Colon, pancreas, appendix, lung and breast are other common primary sites. Gall bladder and bile ducts are extremely rare sources of these metastases. We report one such rare case of krukenberg tumors secondary to gall bladder adenocarcinoma. A thirty-five year old patient came with complaints of mass per abdomen and pain lower abdomen. Ultrasonography of abdomen and pelvis showed two heterogenous mass lesions in pelvis, abdomen and irregular mass in gall bladder. Computed Tomography showed two cystic mass lesions in pelvis and abdomen with thick septations and solid components, which showed moderate enhancement on contrast administration and enhancing soft tissue mass in the gall bladder. Laparotomy was done and showed bilateral ovarian masses and shrunken hard gall bladder. Total abdominal hysterectomy with bilateral salpingo-oophorectomy with cholecystectomy and infracolic omentectomy was done. Histopathology features were suggestive of krukenberg tumors secondary to adenocarcinoma of gall bladder.

INTRODUCTION: Ovarian metastases (krukenberg tumors) commonly arise from primary tumors of stomach, colon, pancreas and breast ${ }^{1}$. Gall bladder and biliary carcinomas are extremely rare causes of krukenberg tumors ${ }^{2}$. We report one such rare case of krukenberg tumors secondary to gall bladder adenocarcinoma.

CASE PRESENTATION: A thirty-five year old female patient came to our hospital with complaints of mass per abdomen, weight loss and loss of appetite since six months and lower abdominal pain since ten days. No history of vomiting, diarrhea, jaundice, white discharge. Her menstrual cycles were regular. Her last menstrual period was ten days back. Patient was not a known hypertensive/diabetic. On examination, irregular mass of size approximately $24 \times 25 \mathrm{~cm}$ noted in pelvis extending into bilateral iliac, lumbar regions, umbilical region and right hypochondrium. Patient's liver and renal function tests were normal. Her ESR was $25 \mathrm{~mm} \mathrm{Hg}$, Hemoglobin was 12gm, HBsAg and HIV tests were negative. Blood test for CA125 was done and value was $156 \mathrm{U} / \mathrm{ml}$ Ultrasonography (USG) of abdomen and pelvis was done, which showed two heterogenous mass lesions in pelvis and abdomen with solid and cystic components with thick septations and increased vascularity with arterial and venous flow(Figures 1a,1b). Irregular hyperechoic mass was seen in gall bladder (GB) measuring 4x2 cm was seen (Figure 1c). Contrast enhanced computed tomography (CT) of abdomen and pelvis was done. Two cystic mass lesions measuring $20 \times 20 \mathrm{~cm}$ and $18 \times 17 \mathrm{~cm}$ noted in both sides of abdomen and pelvis with thick septations and solid components, which showed moderate enhancement on contrast administration (Figures 2a,2b). Enhancing soft tissue 
mass measuring $4 \times 2 \mathrm{~cm}$ was noted in the gall bladder (Figures 3a,3b). No evidence of ascites or lymphadenopathy. Radiological diagnosis of gall bladder neoplasm with bilateral cystic ovarian masses probably krukenberg tumors were given.

Staging laparotomy was done. Intra-operative findings were bilateral ovarian masses, shrunken gall bladder which was hard in consistency and adherent to omentum (Figure 4). Total abdominal hysterectomy with bilateral salpingo-oophorectomy with cholecystectomy and infracolic omentectomy was done and sent for histopathology. Sections from gall bladder revealed papillary tumor lined by columnar cells showing pleomorphism and altered nuclear cytoplasmic ratio (Figure 5a). Sections from ovarian masses revealed multiple signet ring cells, mucin filled cysts lined by mucous cuboidal cells, loose texture with dilated lymphatics and vascular channels in the stroma (Figure 5b). Features were suggestive of krukenberg tumors secondary to adenocarcinoma of gall bladder.

DISCUSSION: The term Krukenberg tumor ${ }^{3}$, refers to ovarian lesions with sarcomatous stroma and mucin-containing signet-ring cells. Initially these were thought to be unusual primary ovarian malignancies by Krukenberg, a German gynaecologist and pathologist in 1896. These were later recognized as metastatic lesions usually arising from primary cancers of the gastrointestinal tract, especially the stomach and colon.

Metastasis to the ovary is not rare and $5 \%$ to $10 \%$ of all ovarian malignancies are metastasis. Ovarian secondary tumors arise most commonly from primary tumors of stomach. Colon, pancreas, appendix, lung and breast are other common primary sites. Other sites such as gall bladder and bile ducts are extremely rare sources of these metastases $4,5,6,7$. A history of prior malignancy can be obtained in $20 \%$ to $30 \%$ of the time. The primary tumor of the krukenberg tumor can be occult and can go undetected for several years after oophorectomy. Therefore an ovarian metastasis is described as primary krukenberg tumor when the primary site is remains silent ${ }^{8}$.

Patients commonly present with complaints of abdominal mass, pain abdomen, abdominal distension and nonspecific gastrointestinal symptoms. Sometimes patients are asymptomatic. Ultrasonography can be used as the first method of imaging. Ovarian metastasis or Krukenberg tumors are usually asymmetrical bilateral and solid masses. When the tumor consists of cystic or necrotic component, they can present as complex cystic lesions simulating primary cystadenocarcinoma. Chen et al demonstrated in his study that metastatic tumors of the ovary have lower RI and PI values compared to the primary ovarian neoplasms 9.

Computed tomography (CT) is the ideal modality for imaging of krukenberg tumors. The CT appearance of Krukenberg tumors typically consists of oval or kidney-shaped masses, which tend to preserve the ovary contour. Krukenberg tumors are usually bilateral and solid masses. They may be solid, cystic or complex ovarian masses ${ }^{1}, 10$. They are frequently bilateral and usually associated with ascites. They are usually solid or predominantly solid with central necrosis or cysts and may attain a large size. Large, lobulated, multicystic masses with soft-tissue components have also been described. Strong enhancement of solid components or septations is usually seen after contrast administration ${ }^{1}$. Confident distinction between primary and metastatic ovarian cancers is not possible in many cases because of overlapping imaging findings, however bilateral, sharply delineated, purely solid or predominantly solid lesions with necrosis favors the diagnosis of a metastatic ovarian tumor ${ }^{11}$. 
CT is a useful method of evaluating the extent of the tumor particularly the involvement of bowel, pelvic ureter, retroperitoneal and pelvic adenopathy and mesenteric metastasis ${ }^{2}$. CT can evaluate gastrointestinal tract better than ultrasonography. Stomach /bowel wall thickening, cholelithiasis and gall bladder wall thickening / mass, if present can be evaluated with CT.

Sometimes enlarged pelvic lymph nodes may mimic ovarian masses; differential diagnosis can be achieved by seeing the relationships between the lesion and the pelvic ureter ${ }^{11}$. The ovaries are usually located anterior or anteromedial to the pelvic ureters, whereas iliac lymph nodes are lateral or posterolateral to the ureters. Therefore posterior displacement of the ureters indicates an ovarian mass whereas enlarged anterior displacement of the ureter may indicate lymph node enlargement.

The ovaries are enlarged asymmetrically with lobulated outline. Krukenberg tumor is typically free of surface adhesions or peritoneal deposits unlike other ovarian metastasis. Microscopically the epithelial component of the Krukenberg tumor mainly consist mucin- laden signet ring cells. CA-125 levels can be elevated in patients with Krukenberg tumor and shows subsequent reduction after tumor excision 8 .

CONCLUSION: Ultrasonography is the preferred modality in the initial evaluation of ovarian neoplasms. CT gives information about the extent of the disease, invasion of surrounding structures and lymphadenopathy. When CT is done for evaluation of pelvic/ovarian mass, particular attention should be paid to look for any mass lesion in stomach, colon, gall bladder and biliary system. In the preoperative CT evaluation of carcinoma of gall bladder/biliary system, ovaries should be routinely examined and if pelvic /ovarian mass is present possibility of metastasis (krukenberg tumour) to be considered. This case demonstrates that an ovarian metastasis can mimic a primary ovarian tumor clinically and in imaging also.So, in the presence of occult primary tumor, the differential diagnosis of complex ovarian masses should include krukenberg tumor in addition to primary ovarian carcinoma and other ovarian lesions. Radiologist should have a high index of suspicion and should look for any focal gall bladder wall thickening or mass in an asymptomatic patient (no hepatic/gastrointestinal symptoms) with cholelithiasis and cholecystitis and ovarian masses especially if bilateral.

\section{REFERENCES}

1. Kyunghee C. Cho, Burton M. Gold. Computed tomography of krukenberg tumors. AJR 1985; 145:285-288.

2. Ayhan A, Guney I, Saygan-Karamursel B, Tasakiran C. Ovarian metastasis of primary biliary and gall bladder carcinomas. Eur J Gynaecol Oncol. 2001; 22:377-378.

3. Krukenberg F. Ueber das Fibrosarcoma ovarii mucocellulare (Carcinomatodes). Arch Gynecol 1896; 50:287-321.

4. Jarvi K, Kelty CJ, Thomas WE, Gillespie A. Bilateral ovarian metastases from carcinoma of the gall bladder. Gynaecol Oncol.2006; 103:361-362.

5. Jain V, Gupta K, Kudva R, Rodrigues GS. A case of ovarian metastasis of gall bladder carcinoma simulating primary ovarian neoplasm: diagnostic pitfalls and review of literature. Int J Jynecol Cancer.2006; 16:319-21. 
6. Khunamornpong S, Lerwill MF, Siriaunkgul S, Suprasert P, Pojchamarnwiputh S, Chiangmai WN, Young RH.Carcinoma of extrahepatic bile ducts and gall bladder metastatic to ovary: a report of 16 cases. Int J Gynecol Pathol.2008; 27:366-379.

7. Kumar Y, Chahal A, Garg M, Bhutani A. Occult gall bladder carcinoma presenting as a primary tumor in two women: two case reports and review of literature. J Med Case Reports.2010; 4:202.

8. Al-Agha OM, Nicastri D. An in depth looks at krukenberg tumor. Arch Pathol Lab Med 2006; 130:1725-1730.

9. Chen $\mathrm{CY}, \mathrm{Wu} \mathrm{YC}, \mathrm{Yen} \mathrm{MS}$ et al. The power Doppler velocity index, pulsatility index and resistive index can assist in making a differential diagnosis of primary ovarian carcinoma and krukenberg tumor. J Ultrasound Med 2007;26:921-6.

10. Kim SH, Kim WH, Park KJ, Lee JK, Kim JS. CT and MR findings of Krukenberg tumors: comparison with primary ovarian tumors. J Comput Assist Tomogr 1996; 20:393-398.

11. T.Bartalena, M.F.Rinaldi, C.Alboni, G.Giannelli, C.Leioni and G.Rinaldi. Krukenberg tumor from gastric adenocarcinoma: CT findings. The internet journal of radiology 2009, 10(1).

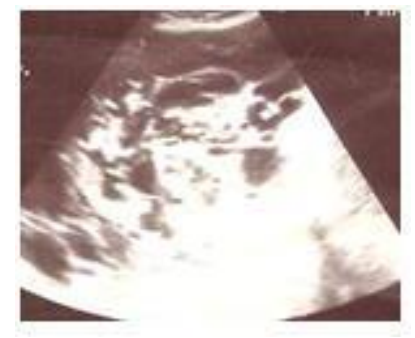

Figure 1a showing ovarian Cystic masses

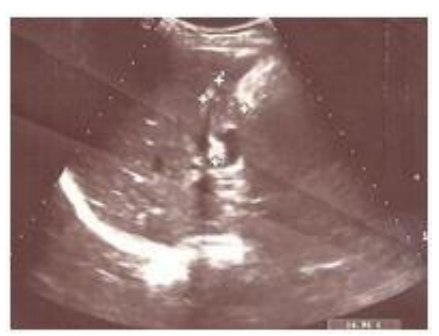

Figure $1 b$ showing increased vascularity in the mass with arterial waveforms

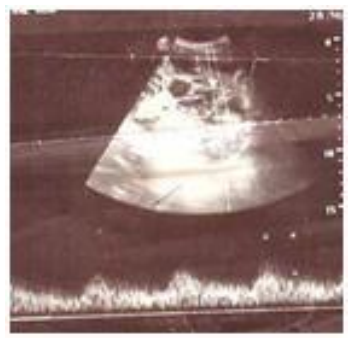

Figure1c showing irregular hyperechoic mass in gall bladder
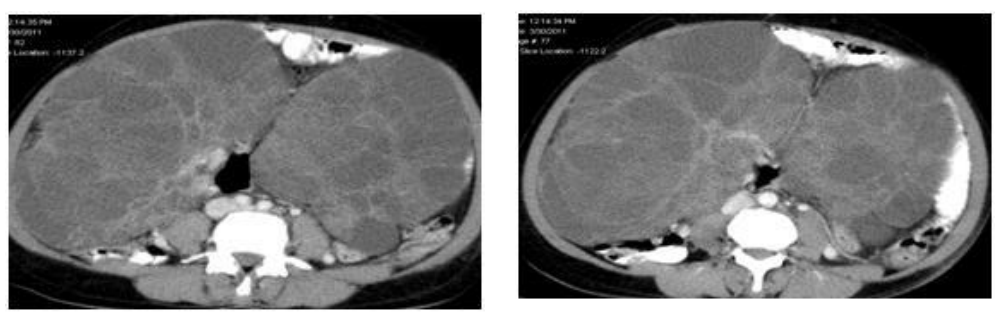

Figures $2 \mathrm{a}, 2 \mathrm{~b}$ showing bilateral ovarian cystic masses with enhancing thick septations and solid components
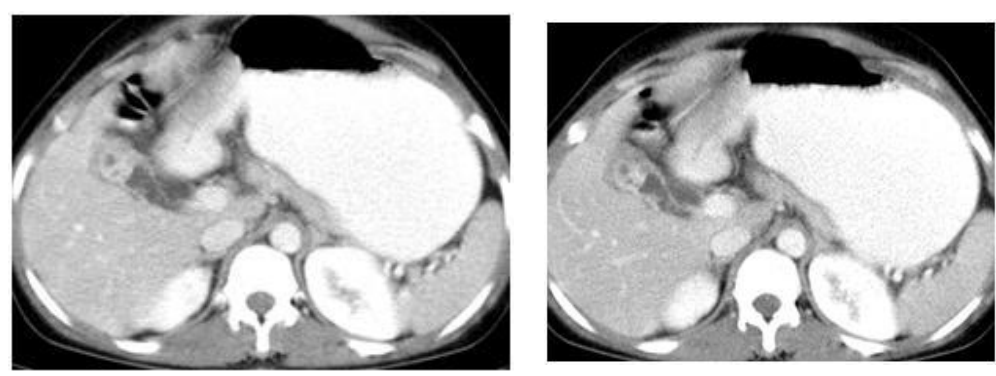

Figures $3 \mathrm{a}, 3 \mathrm{~b}$ showing enhancing mass in gall bladder 


\section{CASE REPORT}

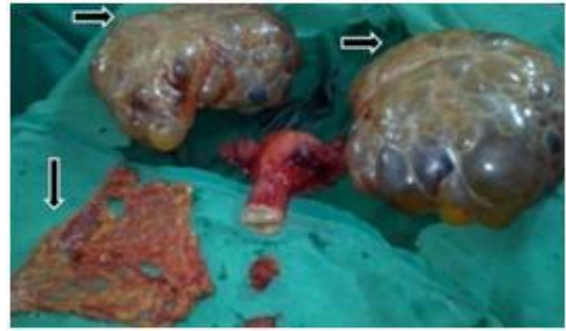

Figure 4 showing gall bladder mass and bilateral ovarian masses

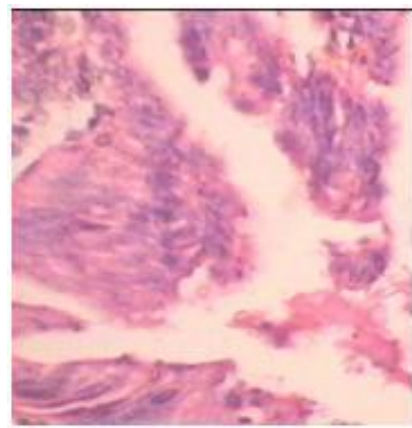

Figure 5a showing papillary tumor with pleomorphism and altered nuclear cytoplasmic ratios in GB

\section{AUTHORS:}

1. Seshu Lakshmi

2. Venkata Umakant

3. Rajeev Donepudi

4. Pavani

5. Bhuvan Krishna.

\section{PARTICULARS OF CONTRIBUTORS:}

1. Associate Professor, Department of RadioDiagnosis, NRI Medical College,Chinnakani.

2. Associate Professor, Department of General Medicine, Mamatha Medical College.

3. Assistant Professor, Department of RadioDiagnosis, Mamatha Medical College.

4. Post Graduate, Department of RadioDiagnosis, Mamatha Medical College.

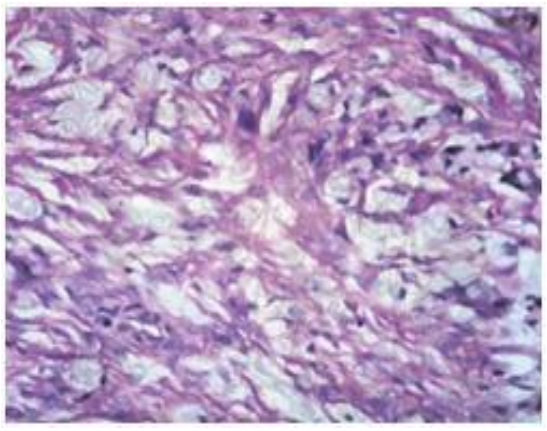

Figure $5 \mathrm{~b}$ showing signet ring cells and mucin infiltrating between residual stromal cells in ovarian masses

\section{Post Graduate, Department of Radio-}

Diagnosis, Mamatha Medical College.

\section{NAME ADRRESS EMAIL ID OF THE} CORRESPONDING AUTHOR:

Dr. Seshu Lakshmi Kodali

105: Garuda's Crest Zion

High School Road

ESI Bus Stop: Gunadala ,Vijayawada.

E-mail:venkatuk@yahoo.com

Date of Submission: 02/07/2013.

Date of Peer Review: 02/07/2013.

Date of Acceptance: 05/07/2013.

Date of Publishing: 08/07/2013 